\title{
LIBERTAD DE ESTABLECIMIENTO DE UN ABOGADO CON LA CONDICIÓN DE MONJE, EN UN ESTADO MIEMBRO DISTINTO DE AQUEL EN EL QUE HA OBTENIDO EL TÍTULO PROFESIONAL. COMENTARIO DE LA STJUE DE 7 MAYO 2019, C- $431 / 17$
}

\author{
FREEDOM OF ESTABLISHMENT OF A MONK WHO \\ HAS OBTAINED THE PROFESSIONAL QUALIFICATION \\ OF A LAWYER IN A MEMBER STATE. COMMENTARY TO \\ THE JUDGMENT OF THE CJEU OF 7 OF MAY 2019,C-431/17
}

\author{
JULIANA RODRÍGUEZ RODRIGO \\ Profesora Titular de Derecho Internacional Privado \\ Universidad Carlos III de Madrid \\ ORCID ID: 0000-0002-5896-983X
}

Recibido: 21.06.2021 / Aceptado: 09.07.2021

DOI: https://doi.org/10.20318/cdt.2021.6303

\begin{abstract}
Resumen: La sentencia objeto de comentario es la respuesta a una cuestión prejudicial planteada por el Consejo de Estado griego. En el caso, el órgano remitente pregunta acerca de la interpretación del artículo 3 de la Directiva 98/5 en relación con la solicitud de inscripción en el Colegio de Abogados de Atenas de un monje que ha obtenido su título profesional en Chipre. Esta norma europea se encarga de regular el ejercicio de la profesión de abogado, de manera permanente, en un Estado miembro distinto de aquel en el que el sujeto ha obtenido el título profesional. El artículo 3 de la Directiva recoge el único requisito que se debe exigir al abogado, cual es, que se inscriba ante la autoridad competente del Estado miembro de acogida y que se encuentre inscrito ante la autoridad competente del Estado miembro de origen. En el supuesto objeto de la sentencia, el abogado cumple con el requisito establecido por el legislador europeo. Así es, se encuentra inscrito en el Colegio de Abogados de Chipre y solicita su inscripción en el Colegio de Abogados de Atenas. Este órgano, precisamente, deniega la inscripción del abogado por su condición de monje. El sujeto recurre esa denegación ante el Consejo de Estado griego y éste plantea cuestión prejudicial al TJUE. El órgano judicial europeo responde a la cuestión exigiendo la inscripción del abogado en el Colegio de Abogados griego y remitiendo al Consejo de Estado la valoración acerca de la proporcionalidad de la medida nacional alegada, que prohíbe a los monjes ejercer como abogados en Grecia.
\end{abstract}

Palabras clave: libertad de establecimiento, abogados, Directiva 98/5, Grecia, monje.

Abstract: The judgment under consideration is the answer to a question referred for a preliminary ruling by the Greek Council of State. In it, the referring court questions the interpretation of Article 3 of Directive 98/5 in relation to the application for registration with the Athens Bar of a monk who obtained his professional qualification in Cyprus. That European rule governs the practice of the profession of lawyer on a permanent basis in a Member State other than that in which the person concerned obtained his professional qualification. Article 3 of the Directive provides only that the lawyer must be registered with the competent authority of the host Member State and that he must be registered with the competent 
authority of the home Member State. In the present case, the lawyer fulfils the requirement laid down by the European legislature. He is registered with the Cyprus Bar and applies for registration with the Athens Bar. The Athens Bar refuses to register the lawyer on the grounds that he is a monk. He appealed against that refusal to the Greek Council of State, which referred the matter to the Court of Justice of the European Union for a preliminary ruling. The European Court answers the question by requiring the lawyer to be registered with the Greek Bar and referring to the Council of State the assessment of the proportionality of the national measure prohibiting monks from being lawyers in Greece.

Keywords: freedom of establishment, lawyers, Directive 98/5, Greece, monk

Sumario: I. Introducción; II. Hechos del caso; III. Problemas que plantea la sentencia; IV. Libertad de establecimiento; 1. Concepto y requisitos; 2. Excepciones; V. Directiva 98/5; 1. Objeto de regulación: libertad de establecimiento de los abogados; 2 . Requisito previo para acceder a la profesión en un Estado miembro distinto a aquel en el que se ha obtenido el título profesional; 3. Requisitos a cumplir para el ejercicio efectivo de la profesión en el Estado miembro de acogida con el título del Estado miembro de origen; VI. Respuesta del Tribunal; VII. Conclusiones.

\section{Introducción}

1. En la sentencia objeto de comentario, el Tribunal de Justicia de la Unión Europea debe pronunciarse acerca de la denegación de inscripción en el Colegio de Abogados de Atenas de un monje que ha obtenido el título en un Estado miembro distinto, concretamente, en Chipre.

En el supuesto se plantea el problema del acceso a la abogacía de ciudadanos europeos que han obtenido el título de abogado en un Estado miembro distinto al país en el que quieren ejercer su profesión.

2. El pronunciamiento del Tribunal europeo es la respuesta a una cuestión prejudicial planteada por el Consejo de Estado griego. En ella, el órgano remitente pregunta acerca de la interpretación del artículo 3 de la Directiva 98/5'.

Según el primer párrafo del precepto mencionado, "Los abogados que deseen ejercer en un Estado miembro distinto de aquel en el que hayan obtenido su título profesional deberán inscribirse ante la autoridad competente de dicho Estado miembro".

3. La Directiva 98/5 es clara en este punto. En virtud del artículo 3, los ciudadanos deberán inscribirse en el Estado miembro en el que quieran ejercer su profesión de abogado, cuando hayan obtenido su título en otro Estado miembro distinto. Al mismo tiempo, del artículo 3 de la Directiva se deduce el deber de los países miembros de inscribir a los ciudadanos europeos que hayan obtenido su título de abogado en un Estado miembro distinto.

El Colegio de Abogados de Atenas, sin embargo, deniega la solicitud de inscripción del sujeto por la condición de monje del abogado, ya que, en la legislación griega los monjes no pueden ejercer la abogacía (art. 6.6 Estatuto de la Abogacía griego).

4. El Tribunal de Justicia distingue entre la obligación de inscripción del abogado con título obtenido en otro Estado miembro, por un lado, y la posibilidad de impedir el ejercicio de la abogacía, por otro. Dicho de otra manera, una cosa es la inscripción en el Colegio de Abogados -y, por tanto, el acceso a la profesión- y otra es el ejercicio de la abogacía. El órgano judicial europeo se limita a responder en el marco de lo primero y deja en manos del Estado de acogida la segunda cuestión.

\footnotetext{
${ }^{1}$ Directiva 98/5, del Parlamento Europeo y del Consejo, de 16 febrero 1998, destinada a facilitar el ejercicio permanente de la profesión de abogado en un Estado miembro distinto de aquel en el que se haya obtenido el título, DOCE L77, de 14 marzo 1998.
} 


\section{Hechos del caso}

5. Los datos del caso son pocos y no ofrecen ninguna duda. Un monje Ireneo, de nombre Monachos Eirinaios, solicita la inscripción en el Colegio de Abogados de Atenas el 12 de junio de 2015, para ejercer como abogado en este país con el título profesional obtenido en Chipre².

6. El 18 de junio de 2015, el Colegio de Abogados rechaza su solicitud amparándose en el Derecho griego, según el cual, no puede tener la condición de monje el abogado que ejerza en Grecia (art. 6.6 del Estatuto de la Abogacía griego) (apartado 10).

El Colegio de Abogados griego justifica la normativa nacional, entre otros, en el hecho de que la condición de monje puede no garantizar la independencia que debe caracterizar el ejercicio de la abogacía (apartado 18).

7. El 29 de septiembre de 2015, el abogado impugna la denegación del Colegio profesional y lo hace ante el Consejo de Estado. En el marco del recurso, este órgano griego plantea la siguiente concreta pregunta al Tribunal de Justicia: “¿Debe interpretarse el artículo 3 de la Directiva 98/5 en el sentido de que el legislador nacional puede prohibir la inscripción de un monje de la Iglesia de Grecia como abogado en los registros de la autoridad competente de un Estado miembro distinto de aquel en el que adquirió su título con el fin de ejercer allí su profesión con el título de origen, ya que los monjes de la Iglesia de Grecia no pueden, con arreglo al Derecho nacional, inscribirse en los registros de los colegios de abogados por no cumplir, debido a su condición, determinados requisitos indispensables para el ejercicio de la abogacía?" (apartado 21).

\section{Problemas que plantea la sentencia}

8. Como se ha comentado antes, son dos las cuestiones que plantea el Tribunal de Justicia en la sentencia. El órgano judicial europeo distingue nítidamente entre dos planos distintos de la misma realidad: acceso y ejercicio.

9. Por un lado, incide en que, según el artículo 3.2 de la Directiva 98/5, el único requisito que se exige para acceder a la profesión de abogado en el Estado miembro de acogida es la inscripción ante la autoridad competente de dicho Estado. Y, para proceder a dicha inscripción, el ciudadano deberá presentar una certificación de su inscripción ante la autoridad competente del Estado miembro de origen ${ }^{3}$; requisito que se cumple en el caso $^{4}$.

10. Cuestión distinta es la relativa al propio ejercicio de la profesión en el Estado miembro de acogida, el cual, según el artículo 6.1 de la Directiva 98/5, estará sometido a las reglas profesionales y deontológicas existentes en ese Estado. Entre ellas, en Grecia, se encuentra la mencionada más arriba, aquella que prohíbe el ejercicio de la profesión a los monjes (art. 6.6 del Estatuto de la Abogacía griego).

11. El Tribunal de Luxemburgo se centra en responder a la cuestión prejudicial desde la primera de las dos vertientes. En relación con la segunda, pone de manifiesto que debe ser el órgano remitente quién determine si la prohibición de ejercicio de la abogacía a los monjes es proporcional al objetivo perseguido con ella (apartado 35). Si lo fuera, se podría considerar válida. Si no lo fuera, atentaría contra la libertad de establecimiento del artículo 49 TFUE.

\footnotetext{
${ }^{2}$ Monje Ireneo es un monje de monasterio de Petra, situado en Karditsa (Grecia) (apartado 12). El Colegio de Abogados de Atenas es el Dikigorikos Syllogos Athinon (DSA) (apartado 2).

3 STJUE 17 julio 2014, Torresi, C-58/13 y C-59/13, ECLI:EU:C:2014:2088; STJUE 19 septiembre 2006, Comisión vs. Gran Ducado de Luxemburgo, C-193/05, ECLI:EU:C:2006:588, apartado 37; STJUE 19 septiembre 2006, Wilson, C-506/04, ECLI:EU:C:2006:587, apartado 67.

${ }^{4}$ El sujeto se encontraba inscrito en el Colegio de Abogados de Chipre desde el 11 de diciembre de 2014 (apartado 27 Conclusiones de la Abogado General, ECLI:EU:C:2018:1028).
} 


\section{Libertad de establecimiento}

\section{Concepto y requisitos}

12. La Directiva $98 / 5$ es la norma europea que se encarga de regular la libertad de establecimiento de los abogados 5 . Esta libertad europea consiste en el derecho de "acceso a las actividades no asalariadas y su ejercicio, así como la constitución y gestión de empresas y, especialmente, de sociedades, tal como se definen en el párrafo segundo del artículo 54, en las condiciones fijadas por la legislación del país de establecimiento para sus propios nacionales, sin perjuicio de las disposiciones del capitulo relativo a los capitales" (art. 49 TFUE) ${ }^{6}$. Por lo tanto, "quedarán prohibidas las restricciones a la libertad de establecimiento de los nacionales de un Estado miembro en el territorio de otro Estado miembro. Dicha prohibición se extenderá igualmente a las restricciones relativas a la apertura de agencias, sucursales o filiales por los nacionales de un Estado miembro establecidos en el territorio de otro Estado miembro" (art. 49 TFUE).

13. Los únicos requisitos para ser beneficiario de la libertad de establecimiento son los que están recogidos en la propia norma, esto es, que la persona física sea nacional de un Estado miembro y que pretenda establecerse en un país miembro distinto al de su nacionalidad para desarrollar una actividad no asalariada ${ }^{7}$.

El concepto de establecimiento ha sido definido por el Tribunal de Justicia, entre otras y precisamente en relación con abogados, en la sentencia del caso Gebhard ${ }^{8}$. Según el órgano judicial europeo, el establecimiento "implica la posibilidad de que un nacional comunitario participe, de forma estable y continua, en la vida económica de un Estado miembro distinto de su Estado de origen, y de que se beneficie de ello, favoreciendo así la interpenetración económica y social en el interior de la Comunidad en el ámbito de las actividades por cuenta propia (véase, en este sentido, la sentencia de 21 de junio de 1974, Reyners, 2/74, Rec. p. 631, apartado 21)" (apartado 25)9. Del concepto anterior se deduce que el establecimiento debe ser permanente ${ }^{10}$.

\section{Excepciones}

14. No obstante lo anterior, la libertad de establecimiento presenta excepciones a su ejercicio ${ }^{11}$. Así, según establece el artículo 51 TFUE, las actividades que estén relacionadas, aunque sea de manera ocasional, con el poder público, no estarán sometidas a esta libertad europea. Por otro lado, el artículo 52 TFUE dispone que el orden público, la seguridad y la salud públicas son razones para impedir el ejercicio de la libertad de establecimiento.

Respecto de la primera excepción, el Tribunal de Justicia se ha pronunciado en el asunto Reyners en el sentido de entender, en primer lugar, que son las actividades y no la profesión, las que tienen que ser evaluadas para determinar si se encuentran relacionadas con el ejercicio del poder público

\footnotetext{
5 Vid., por todos, J. Rodríguez Rodrigo, Régimen jurídico de la abogacía internacional, Comares, Granada, 2003 y la bibliografía que contiene.

6 Vid., por todos, A.L. Calvo Caravaca/J. Carrascosa González, Mercado único y libre competencia en la Unión Europea, Colex, Madrid, 2003 y la bibliografía que contiene.

7 A.L. Calvo Caravaca/J. Carrascosa González, Mercado único y libre competencia en la Unión Europea, Colex, Madrid, 2003, p. 105; C. MARQuÉs RuIZ, "La libertad de establecimiento y la libre prestación de servicios en la CEE", Revista General de Derecho, núm. 490-491, julio-agosto, 1985, p. 2246.

8 STJCE de 30 noviembre 1995, Gebhard, C-55/94, ECLI:EU:C:1995:411

9 J. Rodríguez Rodrigo, Régimen jurídico de la abogacía internacional, Comares, Granada, 2003, p. 28.

10 A.L. Calvo Caravaca/J. Carrascosa GonzÁlez, Mercado único y libre competencia en la Unión Europea, Colex, Madrid, 2003, p. 105.

11 A.L. Calvo Caravaca/J. Carrascosa González, Mercado único y libre competencia en la Unión Europea, Colex, Madrid, 2003, pp. 157-158.
} 
(apartado 45) ${ }^{12}$. En segundo lugar, teniendo en cuenta las actividades, las más típicas de la profesión de abogado no puede considerarse que impliquen una relación directa y específica con el ejercicio del poder público (apartado 54). Actividades como "el asesoramiento y la asistencia jurídica, así como la representación y la defensa de las partes ante los Tribunales, aun cuando la intervención o asistencia del Abogado sea preceptiva o constituya una exclusividad impuesta por la ley" (apartado 52). En este sentido, "que las prestaciones profesionales que implican contactos, incluso regulares y orgánicos, con los órganos jurisdiccionales y hasta una colaboración obligatoria a su funcionamiento, no constituyen sin embargo una participación en el ejercicio del poder público" (apartado 51).

En relación con la segunda excepción, el Tribunal de Justicia considera que el recurso al orden público "requiere, en todo caso, aparte de la perturbación social que constituye toda infracción de la ley, que exista una amenaza real y suficientemente grave que afecte a un interés fundamental de la sociedad" (apartado 35 de la STJCE, de 27 octubre 1977, Bouchereau, asunto 30-77, ECLI:EU:C:1977:172).

15. Por otro lado, la jurisprudencia del Tribunal europeo también incluye el interés general como motivo para condicionar el ejercicio de las libertades europeas de establecimiento y de prestación de servicios (entre otras, STJCE de 28 abril 1977, Thieffry, asunto 71/76, ECLI:EU:C:1977:65, apartados 12 y 15; STJCE de 20 mayo 1992, Ramrath, C-106/91, ECLI:EU:C:1992:230, apartado 29; STJCE de 30 noviembre 1995, Gebhard, C-55/94, ECLI:EU:C:1995:411, apartado 37; STJCE de 31 marzo 1993, Kraus, C-19/92, ECLI:EU:C:1993:125, apartado 32). Por esta razón, "el acceso a algunas actividades por cuenta propia y su ejercicio pueden estar supeditados a la observancia de determinadas disposiciones legales, reglamentarias o administrativas, justificadas por razones de interés general, tales como las normas de organización, de aptitud, de deontología, de control y de responsabilidad (véase la sentencia de 28 de abril de 1977, Thieffry, 71/76, Rec. p. 765, apartado 12). Estas disposiciones pueden prever, en particular, que el ejercicio de una actividad especifica quede reservado, según el caso, a aquellas personas que sean titulares de un diploma, certificado u otro título, a las que pertenezcan a un Colegio profesional o bien a las que estén sometidas a determinada disciplina o control. Dichas disposiciones pueden también establecer los requisitos para la utilización de los títulos profesionales, como el de «avvocato»" (apartado 35 de la STJCE de 30 noviembre 1995, Gebhard, C-55/94, ECLI:EU:C:1995:411).

No obstante lo anterior, debido al carácter absoluto de las libertades europeas, toda medida que suponga un obstáculo o una restricción a su ejercicio debe concurrir de manera excepcional y cumpliendo los siguientes cuatro requisitos: "que se apliquen de manera no discriminatoria, que estén justificadas por razones imperiosas de interés general, que sean adecuadas para garantizar la realización del objetivo que persiguen y que no vayan más allá de lo necesario para alcanzar dicho objetivo" (STJCE de 30 noviembre 1995, Gebhard, C-55/94, ECLI:EU:C:1995:411, apartado 37; en relación con los dos últimos requisitos, vid., STJCE de 31 marzo 1993, Kraus, C-19/92, ECLI:EU:C:1993:125, apartado 32; STJCE de 20 mayo 1992, Ramrath, C-106/91, ECLI:EU:C:1992:230, apartado 30). Respecto a la exigencia de la necesidad de la limitación, para comprobar su concurrencia se ha tener en cuenta que no exista otra medida menos restrictiva que consiga alcanzar el mismo objetivo ${ }^{13}$.

\section{Directiva 98/5}

\section{Objeto de regulación: libertad de establecimiento de los abogados}

16. La Directiva 98/5 regula el ejercicio de la libertad de establecimiento de los abogados europeos en el territorio de un Estado miembro distinto de aquel en el que han obtenido el título profesional (arts. 1.1 y 1.2). La Directiva ha sido transpuesta a ordenamiento español a través del Real Decreto

${ }^{12}$ STJCE de 21 junio 1974, Reyners, asunto 2-74, ECLI:EU:C:1974:68

${ }_{13}$ STJCE 3 diciembre 1974, Van Binsbergen, asunto 33/74, ECLI:EU:C:1974:131; STJCE 4 diciembre 1986, Comisión vs. RFA, C-205/84, ECLI:EU:C:1986:463. 
936/2001". Y ha sido transpuesta al ordenamiento griego mediante el "Proedriko Diatagma 152/2000, Diefkolynsi tis monimis askisis tou dikigorikoy epaggelmatos stin Ellada apo dikigorous pou apektisan ton epaggelmatiko tous titlo se allo kratos-melos tis EE (Decreto Presidencial 152/2000, por el que se facilita el ejercicio permanente de la profesión de abogado en Grecia por parte de abogados que han obtenido el título en otro Estado miembro de la Unión Europea") (apartado 17 Conclusiones de la Abogado General).

17. Como vemos, la Directiva no exige que el abogado deba ser nacional de un Estado miembro distinto de aquel en el que pretende ejercer la libertad de establecimiento. No es necesario, por tanto, que el abogado europeo sea nacional de un Estado miembro diferente de aquel en el que quiere ejercer su profesión, lo importante es que haya obtenido el título de abogado en un Estado miembro distinto de aquel en el que quiere desarrollar su actividad (art. 1.1). Ahora bien, en cualquier caso debe tratarse de un ciudadano con nacionalidad de un país de la Unión (art. 1.2) ${ }^{15}$.

En este contexto, hablaremos de Estado miembro de origen, para referirnos al país en el que el ciudadano europeo ha obtenido su título profesional, y de Estado miembro de acogida, en relación con el país en el que el sujeto quiere ejercer su profesión.

18. El legislador europeo regula en la Directiva $98 / 5$ la posibilidad de que el abogado, con título profesional emitido en el Estado miembro de origen, pueda ejercer su profesión con dicho título en el Estado miembro de acogida. Si, por el contrario, el nacional europeo quisiera ejercer su profesión en un Estado miembro distinto de aquel en el que ha obtenido el título profesional y quisiera hacerlo con el título de este país de acogida, debería tener en cuenta, en principio, la Directiva 2005/36, de 7 de septiembre de 2005, relativa al reconocimiento de cualificaciones profesionales ${ }^{16}$.

\section{Requisito previo para acceder a la profesión en un Estado miembro distinto a aquel en el que se ha obtenido el título profesional}

19. Según prescribe el artículo 3 de la Directiva $98 / 5$, el requisito para que el abogado pueda acceder al ejercicio de manera permanente de su profesión en un Estado miembro distinto de aquel en el que ha obtenido el título profesional es la inscripción ante la autoridad competente del Estado miembro de acogida (art. 3.1).

Para ello, para que la autoridad competente del Estado miembro de acogida proceda a inscribir al abogado, deberá éste aportar un certificado de su inscripción en el Estado miembro de origen (art. 3.2). Se podrá exigir que la certificación de la inscripción en el Estado miembro de origen sea de una fecha dentro de los tres meses anteriores a su presentación en el país de acogida (art. 3.2). Por otro lado, la autoridad competente del Estado miembro de acogida notificará a la autoridad competente del Estado miembro de origen la inscripción del abogado (art. 3.2).

20. Como vemos, por tanto, no sólo se exige que el abogado se inscriba en el Estado miembro de acogida, también se requiere que esté inscrito en el Estado miembro de origen. La imposición de ambas condiciones se justifica por el hecho de conseguir, así, eliminar desigualdades y distorsiones de la competencia, derivadas de las distintas regulaciones nacionales en materia de acceso a la profesión de abogado (Considerando 6 Directiva 98/5). Con esta uniformización de requisitos se eliminan obstáculos a la libre circulación de los abogados en la Unión Europea (Considerando 6 Directiva 98/5).

\footnotetext{
${ }^{14}$ Real Decreto 936/2001, de 3 de agosto, por el que se regula el ejercicio permanente de la profesión de abogado con título profesional obtenido en otro Estado miembro de la Unión Europea, BOE núm. 186, de 4 agosto 2001

${ }^{15}$ En este sentido, el Tribunal de Justicia ha establecido que en caso de doble nacionalidad, si una de ellas es europea, el ciudadano cumplirá con el requisito de ser nacional de un Estado miembro para ejercer la libertad de establecimiento (STJCE 7 julio 1992, Micheletti, C-369/90, ECLI:EU:C:1992:295, apartado 15).

${ }_{16}$ DOUE L255, de 30 septiembre 2005.
} 
21. En España, por ejemplo, abogado es aquel que ha obtenido el Grado en Derecho y, además, ha realizado el Máster habilitante de acceso a la profesión y ha superado el examen de acceso que convoca el Ministerio de Justicia. Pues bien, esta persona no tiene por qué estar inscrito en un Colegio de Abogados español, salvo que quiera ejercer su profesión en este país. Si estamos, por tanto, ante un abogado con título español que no ha ejercido en España y que, por ello, no se encuentra colegiado en nuestro país, que quiere desarrollar su actividad en otro Estado miembro, debería antes inscribirse en el Colegio de Abogados español de su domicilio para, después, solicitar la inscripción ante la autoridad competente del Estado miembro de acogida (art. 23 del Real Decreto 936/2001).

Este requisito de la previa inscripción ante la autoridad competente del Estado miembro de origen podría ser considerado una traba a la libertad de establecimiento en algunos casos, sin embargo, como ha sido establecido por el legislador europeo no se podría actuar por este motivo frente al Estado que lo impone en el caso particular. El obstáculo estaría representado, en principio, por la cuota que el abogado debería abonar para inscribirse en el Colegio del Estado miembro de origen en los supuestos, como el español, en los que no sea necesaria la colegiación para tener la condición de abogado y se trate de un profesional que, efectivamente, no se encuentre inscrito en el Colegio de Abogados. Es más, pudiendo reducir este obstáculo, el Colegio de Abogados de Madrid, por ejemplo, lo incrementa, ya que, exige a los ciudadanos con título de un Estado miembro distinto a España, que quieran ejercer en nuestro país con el título de origen, que acrediten que se encuentran inscritos en un Colegio de Abogados del Estado de origen pero en calidad de ejercientes, y no, alternativamente, como no ejercientes; habiendo tenido que pagar el profesional una cuota mayor, en consecuencia.

En la ley de transposición griega, en cambio, se podría eliminar este impedimento al exigir el legislador nacional que la autoridad del Estado miembro de origen que certifique la inscripción sea "la autoridad que expidió el título u otra autoridad competente del Estado de origen" (apartado 18 Conclusiones de la Abogado General). Esto es, no debe ser, necesariamente, un Colegio de Abogados el que aporte la certificación. Con la autoridad que expidió el título como la competente, entre otras, no habría obstáculo de ningún tipo porque partimos de la premisa de que el solicitante ha obtenido su título profesional en ese Estado miembro y, por tanto, siempre existirá esa autoridad que lo ha expedido y que podrá acreditar la condición de abogado, sin que el profesional tenga que inscribirse ex profeso ante ella para cumplir con el requisito. Otra cuestión es que esa autoridad que expidió el título tiene que acreditar la inscripción en el Estado miembro de origen del abogado. Podría pensarse en este punto que, como la inscripción es el elemento que el legislador europeo considera necesario para probar la cualidad de abogado, inscripción es sinónimo de abogado. Pues bien, en estos países en los que no es necesaria la inscripción para obtener la condición de abogado, inscripción podría ser equivalente a constancia pública del título profesional. Como vemos, tan importante es lo que dice la norma como la interpretación que se pueda realizar de la misma. Así es, estas normas deben ser sometidas a la interpretación que mejor conviva con el respeto a la libertad de establecimiento y, cuanto más margen ofrezca el legislador para ello, más fácil será esa adaptación de la normativa a la observancia de la libertad europea.

22. Es aceptable y se puede compartir por todos que es adecuado exigir los mismos requisitos para el acceso a la abogacía en todos los países de la Unión Europea pero, también es cierto, que la libertad de establecimiento no exige que el ciudadano europeo se encuentre previamente establecido en un país miembro de la UE para poder ejercer este derecho en otro Estado miembro. En efecto, con sólo tener la nacionalidad europea el sujeto puede desplazarse a cualquier país de la Unión para ejercer su profesión de forma no asalariada y de manera permanente. Por lo anterior, la exigencia de colegiación previa en el Estado miembro de origen representaría un obstáculo al ejercicio de la libertad europea en los casos en los que el país de origen no exige tal requisito para que el ciudadano pueda tener la condición de abogado -como ocurre en España-. En los supuestos en los que la inscripción en un Colegio de Abogados es condición sine qua non para la adquisición del título profesional de abogado -Francia, por ejemplo-, tiene sentido este requisito y no supondría ningún obstáculo a la libertad de establecimiento. Sin embargo, para aquellos otros casos en los que la colegiación no es necesaria para obtener la cualificación de abogado, exigir este requisito para ejercer en otro Estado miembro podría considerarse una traba a la libertad europea del artículo 49 TFUE. 
Si hay que igualar requisitos en todos los países de la Unión Europea, lo conveniente habría sido igualar a la baja para favorecer la libertad de establecimiento y no, lo que se podría interpretar que ha hecho el legislador, que es igualar, en este punto al menos, al alza, imponiendo a todos la colegiación en el Estado miembro de origen, tanto en casos en los que ésta es necesaria para ser abogado como en aquellos otros países en los que no. En realidad, debemos matizar lo expuesto porque la Directiva habla de inscripción ante la autoridad competente del Estado miembro de origen y, en ningún caso, menciona los Colegios de Abogados como estas autoridades. Lo que deba entenderse por autoridad competente del Estado miembro de origen se deja a la discreción del legislador nacional. En el caso del legislador español, esta autoridad es el Colegio de Abogados del domicilio profesional único o principal -tanto cuando España sea el Estado miembro de origen como cuando lo sea de acogida (arts. 23 y 4 Real Decreto 936/2001, respectivamente)-. En el caso del legislador griego, se trata de la autoridad que expidió el título o cualquiera otra competente. La normativa griega, con la interpretación aportada anteriormente en el parágrafo 21 in fine, no vulneraría la libertad de establecimiento y la española, en estos casos señalados, sí podría hacerlo.

23. Volviendo a la Directiva, este requisito previo de inscripción es el que ha sido objeto de armonización por parte de la norma (apartado 26). El legislador europeo, por tanto, se centra en regular los aspectos mínimos y formales que se deben exigir para ejercer la libertad de establecimiento en este sector de la abogacía. Condiciones, como decimos, mínimas y formales porque la libertad de establecimiento es un derecho que no está sujeto a ninguna limitación o restricción, salvo, fundamentalmente, por cuestiones de interés público.

\section{Requisitos a cumplir para el ejercicio efectivo de la profesión en el Estado miembro de acogida con el título del Estado miembro de origen}

24. Como indica el artículo 49 TFUE, el ejercicio de la libertad de establecimiento conlleva que el ciudadano europeo reciba un trato nacional en el Estado miembro de acogida ${ }^{17}$. Esto es, tal como recoge el artículo 6 de la Directiva 98/5, independientemente de las normas aplicables al ejercicio de la profesión en el Estado miembro de origen, el abogado debe someterse a estas mismas normas del Estado miembro de acogida en relación con su actividad en dicho Estado.

Efectivamente, en el ejercicio con el título profesional de origen en el Estado miembro de acogida, el nacional europeo deberá cumplir con las mismas normas que regulan la profesión aplicables a los abogados con título obtenido en ese Estado de acogida -principio de trato nacional-.

25. En este sentido, el artículo 6.1 de la Directiva menciona las normas de la profesión y las normas deontológicas como aquellas que deben ser observadas por estos abogados que ejercen en el Estado de acogida con el título profesional del Estado de origen.

Además, el incumplimiento de dichas normas tendrá las consecuencias disciplinarias previstas en el Estado miembro de acogida (art. 7.1). Del procedimiento, sanciones y/o recursos que se sucedan en este Estado, la autoridad del Estado miembro de acogida informará a la autoridad del Estado miembro de origen (art. 7.2). Lo mismo, a la inversa (art. 7.2).

26. En relación con estos estas normas, es el Estado miembro de acogida el que se ocupa de definirlas. En este ámbito nacional el legislador europeo no dispone nada salvo los límites a los que debe someterse la discrecionalidad del legislador nacional.

Así es, la libertad de establecimiento, como ya hemos comentado, es un derecho europeo, por tanto, derecho que debe ser respetado por todos los legisladores nacionales quienes, al formar parte de la Unión Europea, se comprometen a no obstaculizar su consecución (art. 4.3 TUE). Por ello, si bien a

17 A.L. Calvo Caravaca/J. Carrascosa GonzÁlez, Mercado único y libre competencia en la Unión Europea, Colex, Madrid, 2003, pp. 141-142. 
nivel interno se pueden imponer condiciones al ejercicio de la profesión de abogado, estas deben tener en cuenta el compromiso asumido por el Estado en el marco europeo, ya que, estas condiciones deben ser aplicadas a todos los abogados que ejerzan en ese Estado, ya sea con el título profesional del Estado miembro de origen o con el título expedido por ese país y, por tanto, podrían vulnerar la libertad de establecimiento. Así es, como también el legislador nacional se ha comprometido a respetar el principio de no discriminación (art. 6.1 Directiva 98/5), no puede imponer condiciones distintas según el abogado ejerza en su territorio con título nacional o con título de otro Estado miembro. En definitiva, las mismas y únicas condiciones para ejercer la profesión en un país de la Unión no deben suponer un obstáculo a la libertad de establecimiento, salvo que se encuentren justificadas, principalmente, por razones de interés general. En este caso, como ya se ha recogido antes, deben ser no discriminatorias, deben ser proporcionadas al objetivo perseguido con ellas y deben ser necesarias para alcanzar dicho objetivo (STJCE de 30 noviembre 1995, Gebhard, C-55/94, ECLI:EU:C:1995:411, apartado 37).

\section{Respuesta del tribunal}

27. El Tribunal de Justicia pone de manifiesto las dos cuestiones señaladas y responde a una sola de ellas, dejando la otra para que sea el órgano remitente el que la solucione. Lo hace así porque la cuestión prejudicial planteada alude exclusivamente al requisito previo recogido en el artículo 3 de la Directiva 98/5.

28. Efectivamente, el órgano judicial europeo debe limitarse a responder a la cuestión prejudicial del Consejo de Estado griego, por lo tanto, debe centrarse en la interpretación del artículo 3 de la Directiva de establecimiento en el caso particular.

En este sentido, no hay duda alguna. El abogado cumple con el requisito de estar inscrito ante la autoridad competente de Chipre y, por ello, frente a la solicitud de inscripción en el Colegio de Abogados de Atenas, la respuesta debe ser favorable a su petición. Como ya se ha mencionado, para que el abogado pueda ser inscrito en el Colegio de Abogados de Atenas sólo tiene que presentar una certificación de su inscripción en el Estado miembro de origen ${ }^{18}$. Esta premisa se cumple y, por tanto, no hay ninguna razón para no permitir la colegiación en Atenas (apartado 36).

29. Merece más interés la segunda cuestión, respecto de la que el Tribunal europeo no se pronuncia por no haber sido sometida a su interpretación. Se trata de los requisitos que debe cumplir el abogado, ya inscrito ante la autoridad competente del Estado miembro de acogida, para poder ejercer su profesión en ese país. La colegiación en el Estado miembro de acogida no garantiza, por tanto, el ejercicio de la profesión allí, para llegar al estadio final de este proceso y conseguir el objetivo pretendido con la libertad de establecimiento, es necesario ese primer paso de estar inscrito en el Estado miembro de acogida, pero no es suficiente. Así es, el abogado con título del Estado miembro de origen debe, además, respetar las mismas reglas de funcionamiento de la profesión que deben observar los abogados con título nacional, y estas reglas las establece el Estado miembro de acogida. Dicho de otra manera, estas normas deben ser aplicadas, por igual, a todos los abogados inscritos en el Estado miembro de acogida (STJUE 2 diciembre 2010, Jakubowska, C-225/09, ECLI:EU:C:2010:729, apartado 62) ${ }^{19}$.

Una de estas normas, precisamente la que se alega en este caso, es la que indica que un monje no puede ejercer la profesión de abogado en Grecia (art. 6.6 Estatuto de la Abogacía griego). Según el Colegio de Abogados de Atenas, la razón que justifica esta limitación de la ley griega se encuentra en que esta

18 STJUE 17 julio 2014, Torresi, C-58/13 y C-59/13, ECLI:EU:C:2014:2088; STJUE 19 septiembre 2006, Comisión vs. Gran Ducado de Luxemburgo, C-193/05, ECLI:EU:C:2006:588, apartado 37; STJUE 19 septiembre 2006, Wilson, C-506/04, ECLI:EU:C:2006:587, apartado 67.

19 Vid., C. Fernández/I. Moreno-Tapia Rivas, "La libertad de establecimiento de los abogados en la Unión Europea (Comentario a la STJUE de 2 de diciembre de 2010, asunto C-225/09, Jakubowska)”, Noticias de la Unión Europea, n 329, 2012, pp. 177-180. 
condición de monje "no permite ofrecer determinadas garantías, como, en particular, la independencia respecto de las autoridades eclesiásticas a las que está sujeto, la posibilidad de dedicarse plenamente al ejercicio de la abogacía, la capacidad para gestionar asuntos en un contexto de conflicto, la fijación de su establecimiento real en la demarcación del tribunal de primera instancia de que se trate y el respeto de la prohibición de prestar servicios a título gratuito" (apartado 18).

En relación con esta condición impuesta por la normativa nacional, el Tribunal de Luxemburgo remite al Consejo de Estado griego para que compruebe si la misma es contraria a la libertad de establecimiento o si se puede encontrar cubierta por la excepción del interés general.

30. Pues bien, vamos a ir más allá de lo que resuelto por el Tribunal de Justicia en esta sentencia y vamos a intentar ponerlos en el lugar del órgano judicial remitente para dar respuesta a esta cuestión.

Desde ya anticipamos que la prohibición de ejercicio de la profesión de abogado en Grecia a los monjes parece desproporcionada e innecesaria. Y, para llegar a esta conclusión, vamos a ir rebatiendo cada una de las razones que se aportan por el Colegio de Abogados de Atenas en este sentido.

31. Recordamos que la autoridad competente del Estado miembro de acogida argumenta que la condición de monje puede interferir en su independencia con respecto a las autoridades eclesiásticas, puede impedir una dedicación plena a la abogacía, puede determinar su incapacidad para gestionar conflictos, puede impedir tener un establecimiento real en la demarcación del tribunal de primera instancia correspondiente y puede condicionar el respeto de la prohibición de prestar servicios de manera gratuita.

Empezando por la primera razón esgrimida, su falta de independencia de las autoridades eclesiásticas, el mismo argumento podría alegarse en relación con cualquier abogado, sea monje o no, respecto de cualquier persona o institución con la que mantenga una relación de subordinación o dependencia ${ }^{20}$. Por lo tanto, no es necesario establecer esta limitación concreta, en relación con los monjes, para alcanzar el objetivo de independencia en el ejercicio de la abogacía. Además, el abogado debe ser libre de aceptar los casos que quiera defender y, si aceptar algún asunto le pudiera suponer un problema deontológico, rechazándolo estaría resuelta la incompatibilidad. Por lo tanto, la medida, también, es desproporcionada al objetivo de independencia pretendido. En cualquier caso, abundando en esta idea, quizá el monje consiguiera un compromiso de sus autoridades eclesiásticas de respetar su independencia (apartado 78 Conclusiones de la Abogado General).

En relación con la segunda razón, la relativa a la imposibilidad de dedicación exclusiva a la abogacía, esto sí podría no ser cumplido por un monje precisamente por su vinculación eclesiástica. Sin embargo, primero debería determinarse si la condición de monje podría considerarse como ejercicio de otra profesión y, por ello, podría impedir la dedicación exclusiva a la abogacía ${ }^{21}$. Y, en segundo lugar, no es necesario concretar este impedimento en los monjes, cualquier abogado puede verse inmerso en este motivo de incompatibilidad. En todo caso, igualmente como en relación con la razón anterior, el monje podría llegar a un acuerdo con las autoridades religiosas para permitirle dedicar tiempo suficiente al ejercicio de la profesión y poder cumplir, así, con este requisito de dedicación exclusiva a ella (apartado 78 Conclusiones de la Abogado General).

En tercer lugar, la incapacidad para gestionar situaciones en caso de conflicto no debe ser exclusiva de los monjes, cualquier persona, religiosa o no, puede no saber gestionar una situación de conflicto si su carácter y/o su forma de pensar le impiden ponerse en el lugar del otro para intentar poner fin a una disputa. Por ello, la limitación, por esta razón, resulta desproporcionada e innecesaria al objetivo pretendido.

En cuarto lugar, el hecho de que la condición de monje le impida tener un establecimiento real en la demarcación del tribunal de primera instancia correspondiente podría ser verdad pero, igual que

${ }_{20}$ Vid., en el sentido de la incompatibilidad en el ejercicio de la profesión de abogado y de auditor en Países Bajos, STJUE 19 febrero 2002, C-309/99, Wouters, ECLI:EU:C:2002:98

${ }^{21} \mathrm{Vid}$., en relación con la posible consideración de la actividad religiosa como profesión en Grecia, M. GonzÁlez SÁnchEZ, "La condición de monje no impide ejercer como abogado en la Unión Europea (1). Sentencia del Tribunal de Justicia (Gran Sala), de 7 de mayo de 2019, asunto C-431/17: Monje Ireneo v. Colegio de Abogados de Atenas", La Ley Unión Europea, nº 72 , julio 2019. Según este autor, en Grecia los ministros de culto de la Iglesia Ortodoxa tienen un estatuto similar al de funcionario público. 
en caso anterior, no tiene que ser exclusivo de los monjes. También puede haber abogados no monjes que, por sus circunstancias personales, no tengan establecimiento en ese lugar y no por eso se les impide acceder a la profesión de abogado en Atenas. Se podrían ver sometidos a alguna sanción o consecuencia en el momento en el que se descubra ese incumplimiento pero no se les impediría a priori el ejercicio de la abogacía. En todo caso, igualmente como en relación con las razones anteriores, las autoridades eclesiásticas podrían permitir al sujeto tener un establecimiento en la demarcación requerida (apartado 78 Conclusiones de la Abogado General).

Por último, la condición de monje, según el Colegio de Abogados de Atenas, no permite garantizar el cumplimiento de la prohibición de prestar servicios de forma gratuita. De nuevo, nos encontramos ante una circunstancia de la incumbencia exclusiva del monje, quien, por ejemplo, podría cobrar honorarios -si está obligado a ello- y donar los mismos a la institución que él quisiera o a la propia autoridad eclesiástica a la que pertenece (apartado 78 Conclusiones de la Abogado General). Lo mismo que podría hacer cualquier otro abogado que no fuera monje y no quisiera cobrar todos o algunos de los servicios prestados.

32. En resumen, como ya habíamos adelantado, la prohibición de ejercicio de la profesión de abogado a los monjes podría ser una restricción de la libertad de establecimiento que no se encontraría justificada en razones de interés general.

Todos los argumentos esgrimidos pueden ser aplicados a cualquier persona y no sólo a aquellas que tengan la condición de monje. Al margen de que el abogado sea monje, debe actuar de manera independiente y no aceptar influencias de ningún tipo, debe tener un establecimiento en la demarcación del tribunal de primera instancia ante el que ejerza, debe cumplir con la prohibición de no prestar servicios de manera gratuita y debe dedicarse exclusivamente a la profesión de abogado. Y queda en la esfera del sujeto la capacidad de gestión del conflicto. Dependiendo de esto último el éxito en su profesión será mayor o menor pero, en todo caso, ésta es una cuestión que concierne sólo al sujeto y nunca al Estado.

Estos argumentos, además de que pueden aplicarse a cualquier abogado, deberían ser requisitos a cumplir por parte de los profesionales en el ejercicio de la abogacía, pero nunca podrían ser requisitos previos, eliminatorios, que impidan el acceso al ejercicio de la profesión. Como mucho, podrían ser requisitos deontológicos que conllevaran, a posteriori -una vez el abogado ha empezado a ejercer-, una sanción; la cual podría ser la prohibición de ejercicio, claro está (STJUE 2 diciembre 2010, Jakubowska, C-225/09, ECLI:EU:C:2010:729, apartado 57). Estamos de acuerdo con la Abogado General en este sentido de que no se debe suponer cuál va a ser el comportamiento del abogado y sancionar sólo la actuación real del profesional que infrinja las reglas de funcionamiento de la abogacía en el Estado de acogida (apartados 68 y 73 Conclusiones).

Por último, la consideración de estos requisitos como desproporcionados e innecesarios supondría que no podrían imponerse a los abogados con título profesional de origen. En este escenario, por el principio de no discriminación, deberían también dejar de imponerse a los monjes con título profesional de Grecia para no incurrir en una discriminación à rebours ${ }^{22}$ (art. 6.1 Directiva 98/5).

\section{Conclusiones}

33. La sentencia del Tribunal de Justicia objeto de comentario es impecable. Pone de manifiesto los dos planos, el europeo y el nacional, que concurren en el caso. El órgano judicial europeo se limita a actuar en el primero de ellos, interpretando el artículo 3 de la Directiva 98/5. En relación con el segundo, simplemente porque no ha sido objeto de la cuestión prejudicial planteada ante él, se limita a remitir al Consejo de Estado griego que pregunta.

Es importante destacar esto último, que el Tribunal no se pronuncia en relación con la norma interna del Estado en cuestión porque no ha sido sometida a su interpretación pero no porque no pueda hacerlo en cualquier otro caso en el que se le pregunte por ella. Así es, la norma interna litigiosa, la que

${ }^{22}$ A.L. Calvo Caravaca/J. Carrascosa González, Mercado único y libre competencia en la Unión Europea, Colex, Madrid, pp. 132-134. 
indica que los monjes no pueden ejercer la profesión de abogado, puede afectar a la libertad de establecimiento de los profesionales que quieran ejercer en Grecia habiendo obtenido su título en otro Estado miembro. Éste precisamente es el caso y el Tribunal de Justicia podría haberse pronunciado en relación a ella si hubiera sido preguntado por esta cuestión.

34. En relación con la aplicación del artículo 3 de la Directiva 98/5, el órgano judicial europeo indica que el precepto establece el único requisito que debe ser exigido al abogado con título de otro Estado miembro para que acceda a la profesión en el Estado miembro de acogida, cual es, la inscripción ante la autoridad competente del Estado miembro de origen y la solicitud de inscripción ante la autoridad competente del Estado miembro de acogida. Si el profesional cumple con este único requisito de encontrarse inscrito ante la autoridad del Estado miembro de origen, la autoridad del Estado miembro de acogida no puede negar la inscripción. Esto es lo que ocurre en el caso. El sujeto se encuentra inscrito en el Colegio de Abogados de Chipre y solicita su inscripción en el Colegio de Abogados de Atenas. Este órgano, sin embargo, deniega su inscripción por la condición de monje del solicitante. Según el Estatuto de la Abogacía de Grecia, los monjes no pueden ejercer la profesión de abogado.

35. El Tribunal de Justicia, interpretando el artículo 3 de la Directiva 98/5 en el caso particular, indica que el sujeto debe ser inscrito en el Colegio de Abogados de Atenas porque cumple con el único requisito exigido para ello. Sin embargo, deja que sea el órgano remitente el que valore si esa prohibición de ejercicio de la abogacía a los monjes resulta proporcional. Esto es, lo que hace el Tribunal de Luxemburgo es tener en cuenta las excepciones a la libertad de establecimiento, entre las que se encuentra, el interés general siempre que la limitación o impedimento de la libertad de establecimiento no se aplique de manera discriminatoria, sea proporcional al objetivo perseguido y sea necesaria para conseguir ese objetivo. En el caso particular, la regulación interna griega debe ser coherente con la libertad de establecimiento de los abogados, debe, por tanto, no obstaculizar este derecho en relación con los profesionales que quieran ejercer en el Estado miembro de acogida con el título del Estado miembro de origen. No obstante, si esa regulación interna, limitativa de la libertad de establecimiento, se encuentra justificada por razones de interés general, será válida. En este sentido, deja en manos del órgano remitente valorar esta cuestión para saber si la medida restrictiva puede ser considerada válida pese a obstaculizar el derecho de establecimiento. 